\title{
Working memory and strategies in syllogistic-reasoning tasks
}

\author{
K. J. GILHOOLY, R. H. LOGIE, N. E. WETHERICK, and V. WYNN \\ Aberdeen University, Aberdeen, Scotland
}

\begin{abstract}
It has often been asserted that working-memory limitations are a major factor contributing to problem difficulty; for example, Johnson-Laird's (1983) mental-models theory appeals to workingmemory limitations to explain the difficulty of syllogistic reasoning. However, few studies have directly explored working memory in problem solving in general or syllogistic reasoning in particular. This paper reports two studies. In the first, working-memory load was varied by presenting syllogistic tasks either verbally or visually (so that the premises were continuously available for inspection). A significant effect of memory load was obtained. In the second study, premises were presented visually for a subject-determined time. Dual-task methods were used to assess the role of working-memory components, as identified in Baddeley's (1986) model. Syllogistic performance was disrupted by concurrent random-number generation but not by concurrent articulatory suppression or by concurrent tapping in a preset pattern. Furthermore, the concurrent syllogism task interfered with random generation and to a lesser extent with articulatory suppression, but not with tapping. We conclude that while the central-executive component of working memory played a major role in the syllogistic-task performance reported here, the articulatory loop had a lesser role, and the visuospatial scratch pad was not involved.
\end{abstract}

It has often been asserted in discussions of problem solving that working-memory load is a major factor in determining task difficulty (e.g., Gilhooly, 1988, 1991; Newell \& Simon, 1972; Sanford, 1985). Although this general notion has considerable intuitive plausibility, there appear to be very few studies that have directly addressed the role of working memory in problem solving. The present paper aims to remedy this deficit in the area of syllogistic reasoning. A number of theorists have proposed that working memory is implicated in syllogistic reasoning (Fisher, 1981; Johnson-Laird, 1983; Johnson-Laird \& Byrne, 1991; Sternberg \& Turner, 1981), but the issue has not been directly investigated to date. We will first outline the nature of syllogistic-reasoning tasks, then the main theories of syllogistic performance, and finally the particular working-memory model used in our studies.

Syllogistic arguments invite reasoning about category relationships and involve two statements (premises) that are assumed to be true, for example, "All dogs are mammals" and "All corgis are dogs." One premise relates the subject of the argument (corgis) to the middle term (dogs), and the other premise relates the middle term to the predicate (mammals). The types of relationships between the subject, predicate, and middle terms used in syllogistic arguments are those of set inclusion, overlap, and exclusion, namely, all, some, none, and some not. The subjects' task is to indicate what conclusion, if any, can be drawn relating the subject and predicate terms to

\footnotetext{
Correspondence should be addressed to K. J. Gilhooly, Psychology Department, Aberdeen University, Aberdeen AB9 2UB, Scotland (e-mail: k.gilhooly@aberdeen.ac.uk).
}

one another. In the example above, it can be validly inferred that "All corgis are mammals." The number of possible syllogistic-argument structures is quite large. Since each of the two premises can involve any one of four logical relations, there are 16 such combinations. Furthermore, there are four possible ways, known as "figures," in which the subject, predicate, and middle terms can be arranged in the two premises (see Table 1).

Combining the four possible figures with the 16 possible combinations of logical relations yields 64 logically distinct argument forms. Interestingly, some argument forms are almost invariably handled correctly and some almost always lead to error. For example, taking two syllogisms that differ in both the figure and the type of relations used, Johnson-Laird and Bara (1984) found that 19 out of their 20 subjects correctly solved the syllogism "All $A$ are $B$; All $B$ are $C$; Therefore, ?" (Answer: "All $A$ are $C$ '), whereas none of the 20 subjects solved the syllogism "Some $B$ are not $A$; All $B$ are $C$; Therefore, ?" (Answer: "Some $C$ are not $A$ '). Despite more than 60 years of experimental and theoretical study (e.g., Begg \& Denny, 1969; Johnson-Laird \& Bara, 1984; Wetherick \& Gilhooly, 1990; Wilkins, 1928; Woodworth \& Sells, 1935), there is still no generally accepted account of how people process such arguments. We will now briefly outline some of the main approaches that have been proposed to explain syllogistic performance.

Following the approach of Galotti, Baron, and Sabini (1986), it is useful to divide theoretical approaches to syllogistic-task performance into models accounts and rules accounts. In models accounts, subjects are seen as generating one or more internal representations consistent with particular interpretations of each premise and 
Table 1

The Four Figures of the Syllogism

\begin{tabular}{cccc} 
Figure 1 & Figure 2 & Figure 3 & Figure 4 \\
\hline $\mathrm{M}-\mathrm{P}$ & $\mathrm{P}-\mathrm{M}$ & $\mathrm{M}-\mathrm{P}$ & $\mathrm{P}-\mathrm{M}$ \\
$\mathrm{S}-\mathrm{M}$ & $\mathrm{S}-\mathrm{M}$ & $\mathrm{M}-\mathrm{S}$ & $\mathrm{M}-\mathrm{S}$ \\
\hline
\end{tabular}

Note $-M=$ middle term; $S=$ subject of the conclusion; $P=$ predicate of the conclusion.

then deriving from these premise representations one or more possible conclusion representations. In rules accounts, subjects are seen as operating solely on the form of the premises, without generating intermediate representations, in order to reach conclusions. In general terms, rules accounts propose more superficial, less cognitively demanding processes than do models accounts. So, rules accounts suggest that syllogism tasks would place fewer demands on working memory than would models accounts. Existing approaches will now be discussed in terms of the rules versus models framework. First, we consider rules accounts.

An early proposal was that subjects respond on the basis of the "atmosphere" of the argument (Sells, 1936; Woodworth \& Sells, 1935). If the premises both involved "some," it was held that subjects were thus "set" for a "some" conclusion; similarly, if both premises were "all," a set toward "all" conclusions would be built up. Classing the four logical relations as positive (all and some) or negative (none and some not) and universal (all and none) or particular (some and some not), the atmosphere hypothesis can be neatly summarized as two rules (Begg and Denny, 1969):

Atmosphere Rule 1: If at least one premise is negative, the conclusion is negative, otherwise it is positive.

Atmosphere Rule 2: If at least one premise is particular, the conclusion will be particular, otherwise it is universal.

For example, if the syllogism is "Some guard dogs are fierce dogs; No corgis are guard dogs," and the subject of the argument is "corgis," the atmosphere hypothesis would predict the response "Some corgis are not fierce dogs." (The correct response is "No valid conclusion possible.") If the subject of the argument is specified, then the two atmosphere rules will give definite predicted responses to all syllogistic-argument forms. However, in some experimental paradigms (e.g., Johnson-Laird, 1983; Johnson-Laird \& Byrne, 1991; Wason \& Johnson-Laird, 1972), the subject of the argument is not specified and could be either of the non-middle terms; in such studies, the atmosphere rules predict two possible responses of the same form corresponding to choice of one of the nonmiddle terms as the subject of the argument. Thus, in the above example, if the subject was not specified, the atmosphere hypothesis would predict that responses would be split equally between "Some corgis are not fierce dogs" and "Some fierce dogs are not corgis." Overall, the atmosphere hypothesis has been found to account well for the response data in a number of studies (Begg \& Denny, 1969; Dickstein, 1978; Revlis, 1975).

The atmosphere hypothesis suggests that subjects combine information from both premises to generate a conclusion. A still simpler "rules" possibility, known as "matching," has been explored by Wetherick (1989; Wetherick \& Gilhooly, 1990). According to the matching hypothesis, subjects match the logical form in the conclusion to the more conservative of the premises. A single rule can express this idea as follows:

Matching Rule: Give as the conclusion a proposition of the same logical form as the more conservative of the premises, where the logical forms are ordered for conservatism, from most to least, 'No,' 'Some not,' 'Some,' and 'All.'

In the example syllogism used above, given corgis to be the subject of the argument, the matching hypothesis would predict the response "No corgis are fierce dogs." This may be contrasted with the atmosphere prediction of "Some corgis are not fierce dogs" and with the correct response of "No valid conclusion possible." Evidence for the existence of matching as a strategy was reported by Wetherick and Gilhooly (1990), who found that their 36 subjects could be divided rather cleanly into a "matching' subgroup of 24 , who performed well on syllogisms for which matching gave the correct conclusion and poorly otherwise, and a "logic" subgroup of 12 , who performed well both on syllogisms susceptible to a matching approach and on syllogisms to which matching gave an incorrect conclusion.

The "natural logic" or "mental logic" approaches of Braine (1978; Braine \& Rumain, 1983) and Rips (1983) to propositional reasoning would fit the "rules" category of models, but they do not seem to have been applied to categorical syllogisms, which are our focus.

The models approach would include the proposals of Erickson (1974, 1978), Fisher (1981), Johnson-Laird (1983), Johnson-Laird and Bara (1984), Johnson-Laird and Byrne (1991), and Sternberg (Guyote \& Sternberg, 1981; Sternberg \& Turner, 1981). Erickson and Sternberg suggest that the intermediate representations may take the form of visual images akin to Euler circles, whereas Johnson-Laird and Fisher are less specific about the form of representation. Johnson-Laird's mental-models approach is the best developed of this class of theory and has been applied to many reasoning tasks subsequent to its initial strong association with explaining syllogistic reasoning. The main assumptions of the mental-models approach are that (1) subjects form representations of the premises consisting of tokens of the terms linked together so as to exemplify the stated categorical relationships (all, some, none, some not) and (2) subjects then seek to combine the two premise representations into integrated representations from which possible conclusions can be read. In some cases, there is supposed to be only one way in which the premise representations can be combined, but in other cases, there may be two or, more often, three possibilities. If subjects did explore all possible premise 
combinations, then they would perform perfectly. Suboptimal performance is explained by failure to consider all ways of combining premise information because of working-memory limitations. The theory predicts that one-model syllogisms will be easier than multiple-model syllogisms, and this proves to be the case. However, as Wetherick (1989; Wetherick \& Gilhooly, 1990) noted, this result is not so conclusive as it may appear because one-model syllogisms can also be solved by matching, whereas three-model syllogisms cannot, and two-model syllogisms are mixed between those susceptible to matching and those not (hence, perhaps, their intermediate difficulty, on average). Nevertheless, the mental-models approach to syllogistic performance is impressive in accounting for a range of data with fairly few assumptions, although it does not make detailed syllogism-by-syllogism predictions as do the rule-based atmosphere and matching approaches.

It is noteworthy that the models approaches of Sternberg, Fisher, and Johnson-Laird specifically propose a role for working memory in syllogistic reasoning. The following quotation from Johnson-Laird (1983) is particularly apposite:

The effects of both number of models and figure arise from an inevitable bottleneck in the inferential machinery: the processing capacity of working memory, which must hold one representation in a store, while at the same time the relevant information from the current premise is substituted in it. This problem is not obviated by allowing the subjects to have the written premises in front of them throughout the task: the integration of premises has to occur in working memory, unless the subjects are allowed to use paper and pencil so as to externalize the process. (p. 115)

Thus, there is a strong claim in the mental-models approach that working-memory is intrinsically involved in syllogistic reasoning even when the premises are continuously available to the subjects. Johnson-Laird cites some unpublished correlational evidence relating a proposed measure of working memory processing capacity to syllogistic accuracy, but no direct investigations of working memory in syllogistic-task performance.

The present paper reports two experiments investigating the role of working memory in syllogistic tasks. Despite Johnson-Laird's (1983) argument that working memory is still involved in syllogistic reasoning even when the premises are continuously available, it is clear that when the premises are not continuously available there will be a heavier load on working memory. Hence, the first study seeks to manipulate load on working memory by varying the external availability of the premises to inspection. If integration of premise information requires use of working memory, then adding to working-memory load should reduce accuracy of syllogistic reasoning. The second study uses dual-task methods to load different components of working memory (Baddeley, 1986) during syllogistic-reasoning tasks.

\section{EXPERIMENT 1 \\ Visual Versus Verbal Presentation of Syllogisms}

If premises are presented verbally in close succession, then there has to be some storage of the premise information in working memory before any integration of premise information can take place. Thus, verbal presentation places a greater load on working memory than does continuously available visual presentation and so should lead to more errors. Also, and more specifically, if working memory is involved in the integration of information in the premises, it might be expected that any additional errors resulting from verbal presentation would tend to be errors of incomplete analysis (i.e., by proposing specific conclusions when "no valid conclusion" is correct). According to Johnson-Laird's (1983) mental-models theory, subjects must develop and compare possible conclusions for at least two, and possibly three, alternative models implied by the premises before a conclusion that the syllogism has, in fact, no valid conclusion can be drawn. Memory load may be expected to interfere with the generation of alternative mental models and hence lead to more errors on arguments where "no valid conclusion" is correct.

For purposes of generality, the present study involved not only verbal versus visual presentation, but also arguments where the topic was specified in advance and where it was not.

\section{Method}

Subjects. Seventy-one subjects ( 31 male, 40 female) took part. The subjects were all undergraduate volunteers at Aberdeen University, and they received $£ 2$ for participating. None of the subjects had taken formal instruction in logic.

Design and Procedure. The design involved two groups of subjects, one $(n=29)$ tested in the topic-specified condition (where the subject was told that "the argument is about $S$ ") and one ( $n=$ 42 ) tested in the topic-not-specified condition (where the premises were presented without comment). All subjects solved a series of 20 syllogisms twice, with a short break in between, in the verbal condition (where premises were read aloud once) and in the visual condition (where the premises were displayed on an overhead projector until all subjects had recorded their conclusions). Half of the subjects did the verbal condition first, and half did the visual condition first, crossed with topic specified or not specified. For all syllogisms, the subjects had to generate and write down their solutions rather than select them from a menu of possible conclusions.

General instructions about the syllogism were given verbally at the beginning of the task and included examples of all the types of syllogisms involved in the experimental tasks.

Materials. The series of 20 syllogisms employed $X, Y$, and $Z$ as terms. Each term appeared with equal frequency as the subject, predicate, and middle term in different syllogisms. Five types of syllogisms were presented four times each, in syllogistic Figure 1 and Figure 4 and with the subject term in either the first premise or the second premise. The five types of syllogisms were those having the following logical forms: all-all, all-some, all-none, none-all, and some-none. Of the 20 syllogisms presented, 4 had no valid conclusion, and the remainder were distributed equally over those having all, some, none, and some not conclusions. This selection of 20 syllogisms from the possible 64 ensured that the sub- 
Table 2

Mean Correct Scores (Out of 20) for Visually and Verbally Presented Syllogisms

\begin{tabular}{lccc}
\hline & & \multicolumn{2}{c}{ Type of Presentation } \\
\cline { 2 - 4 } & $n$ & Verbal & Visual \\
\hline Topic specified & 29 & 10.90 & 11.86 \\
Topic not specified & 42 & 11.57 & 13.50 \\
\hline
\end{tabular}

jects' responses were not affected by possible response biases toward any of the five possible responses.

\section{Results and Discussion}

Table 2 shows the mean correct conclusions drawn out of 20 . Analysis of variance showed that the visual condition mean correct score $(12.83, S D=3.19)$ was significantly higher $[F(1,70)=18.47, p<.001]$ than the verbal condition mean score $(11.30, S D=3.96)$. None of the other differences or interactions were significant.

The errors made could be classified into three types: (1) errors of forgetting, in which the conclusions offered included the middle term; (2) errors of incomplete analysis, in which definite conclusions were offered to syllogisms having no valid conclusions; and (3) errors of information integration, in which erroneous conclusions were offered to syllogisms that permitted valid conclusions. The only notable difference in error category scores between the visual and verbal conditions was the higher incidence in the verbal condition of erroneous conclusions that included the middle term (an average of 2.90 in the verbal condition vs. 1.04 in the visual condition). This observation suggests that the effect of working-memory loading in the verbal condition, in which the subjects had to store the premises, was on the retention of the terms rather than on the process of combining information in the premises. Apparently, verbal presentation led the subjects to forget the roles of the three terms and redundantly attempt to relate middle term and subject or middle term and predicate, relationships that had already been stated in the premises.

This study, then, indicates that loading of working memory by the verbal presentation of premises brings about a particular category of error, which is related to storage rather than manipulation. However, the study does not directly bear on the role of working memory in information integration when premises are continuously visually available, as would be the case in working with written arguments. The second experiment, reported below, takes up this issue. According to Johnson-Laird's (1983) analysis, working memory effects should be discernible in the processing of written as well as orally presented arguments.

\section{EXPERIMENT 2 \\ Components of Working Memory in Syllogistic Performance}

Baddeley and colleagues (Baddeley, 1986; Baddeley \& Hitch, 1974; Logie, 1991; Logie, Zucco, \& Baddeley,
1990) have developed and extensively tested a specific model of working memory consisting of three main components: the articulatory loop, the visuospatial scratch pad, and the central executive. The articulatory loop is seen as holding a limited amount of phonological or speechbased information. The visuospatial scratch pad holds a limited amount of visual or spatially coded information. The central executive is seen as "some type of supervisor or scheduler, capable of selecting strategies and integrating information from various sources" (Baddeley, 1986, p. 225) and is similar in concept to Norman and Shallice's (1980) supervisory attentional system. Secondarytask methods have been the prime means for investigating the contribution of the working-memory components to target tasks. Concurrent articulation and concurrent spatial activity are seen as loading the articulatory loop and the visuospatial scratch pad, respectively. So, if a primary task is disrupted by articulatory suppression (e.g., saying " the, the, the ..." continuously) but not by concurrent spatial activity (such as moving the nonpreferred hand in a set pattern), it can be inferred that the primary task involves the articulatory loop, but not the scratch pad. Central-executive involvement is tested for by concurrent random generation of items from a well-defined set (e.g., letters of the alphabet, digits from 1 to 10 , etc.). A number of studies have found these methods to be useful indicators of the relative involvement of the working-memory components in a range of task domains (see, e.g., Baddeley, Lewis, \& Vallar, 1984; Farmer, Berman, \& Fletcher, 1986; Logie, Baddeley, Mane, Donchin, \& Sheptak, 1989; Saariluoma, 1991; Salway, 1991).

The area of reasoning has seen few studies of workingmemory involvement using secondary tasks. Baddeley and Hitch (1974; Hitch \& Baddeley, 1976) found surprisingly little effect of articulatory suppression on accuracy or latency of reponse in their $A B$ grammatical reasoning task. (In this task, subjects had to respond true or false to sentences regarding the order of two subsequent letters, $A$ and $B$. The sentences varied from simple active declaratives such as " $A$ follows $B$ " $[B A]$ to negative passives such as " $A$ is not preceded by $B$ " $[A B]$. A subsequent study by Farmer et al. (1986) did find a small but significant interfering effect of articulatory suppression, but not of spatial suppression, on the more difficult $A B$ tasks. However, Evans and Brooks (1981) found no effect of articulatory suppression on accuracy of conditional reasoning. As Halford, Bain, and Maybery (1984) argued, this may be because Evans and Brooks's reasoning task did not elicit strategies that loaded working memory. To summarize, the existing literature on working memory and reasoning using dual tasks does not strongly implicate the articulatory loop. But, it is clear that the existing literature is incomplete in its coverage of reasoning and of the components of working memory involved in reasoning. The present experiment aims to fill some of the gaps in the literature by examining all three components of working memory in the syllogistic-reasoning task. As has been outlined above, according to model-based ap- 
proaches, a strong working-memory involvement should be demonstrable in syllogistic performance.

\section{Method}

Subjects. The subjects were 48 first- and second-year psychology students ( 16 for each of three tasks; 16 male and 32 female). All were volunteers and were paid $£ 3$ for participating.

Materials. An Elonex computer and keyboard with IBM monochrome monitor was used for display of syllogisms and recording of the subjects' responses. All screen displays were created and all responses recorded using the MEL (Micro Experimental Laboratory) system (Schneider, 1990). A wooden board, $190 \mathrm{~mm} \times$ $190 \mathrm{~mm}$, with four sprung switches arranged in a square was used for the secondary tapping task. The tapping board and a throat microphone were attached by cable to an Atari computer for recording response rates in the secondary tasks.

Design. All subjects carried out 20 syllogistic-reasoning tasks in a control condition and in a dual-task condition in which the reasoning tasks were performed with one of three secondary tasks. The reasoning tasks were the same as those used in Experiment 1. Performance order of control and dual conditions was alternated between subjects.

Procedure. The subjects were seated at a table with the computer monitor and keyboard in front of them and were told to press the space bar when they were ready to begin. Instructions were then shown on the monitor. The subjects were instructed in the nature of the syllogistic task. On each trial, the topic of the argument $(X$, $Y$, or $Z$ ) was specified and the two premises presented. The subjects were instructed to attempt to draw their own conclusions and, when ready, to press the space bar, which caused a menu of five possible responses to be displayed (four possible conclusions relating subject and predicate plus a "no valid conclusion" option). The possible responses were labeled " $a$ " to " $e$ " on the screen. The subjects were instructed to indicate their responses on a normal keyboard by pressing the appropriate one of Keys 1-5, which had the digits covered by labels "a" to "e." This arrangement ensured that the appropriate response keys were readily located and that response interference from the secondary tasks involving digits was minimized. The allocation of keys to correct responses was balanced over trials.

Measures were obtained on each trial of the times the subjects spent viewing the pairs of premises, of the times taken to indicate conclusions after the response alternatives were displayed, and of the reponses made. The intention was that the time taken to view the premises would reflect premise-processing time; however, it was possible that the subjects could carry over some premise processing into the response-indicating phase, and so that time was also recorded to check for any such tendency.

Before starting the experiment proper, the keys for response were pointed out and 2 practice reasoning trials were given, with time and accuracy of response displayed after each trial. This was followed by 40 trials, 20 each in control and dual conditions, without displaying time and response information.

For the subjects who carried out the dual condition first, instructions for the secondary tasks were given verbally after the practice trials. Those carrying out the control task first were instructed on the secondary tasks after 20 trials.

Control condition (all subjects). Each subject was asked if he/she was left or right handed and told to use his/her preferred hand on the computer keyboard. The subjects wore earphones and carried out the reasoning task while listening to a metronome beat ( 1 per second)

Dual conditions. All three secondary tasks were performed in time to the metronome beat, and performance rates were recorded on the Atari computer.

To ascertain their "normal" rate, the subjects carried out control secondary tasks lasting 2 min either before or after the dual task (alternate subjects). The subjects were told to press the space bar when ready to start the experiment, and in addition, they were given the following verbal instructions:

Tapping-“"To your right/left (opposite side to preferred hand) you will see a wooden board. What you have to do is to tap the four switches in a clockwise direction in time to the metronome beat." The board was then concealed from the subjects' view by an open-fronted box covered with black cloth.

Articulatory suppression-The subjects were fitted with a throat microphone and told to repeat the numbers " $1,2,3,4,5$ " continuously in time to the metronome beat.

Random generation-" What you have to do is say the numbers $1,2,3,4,5$ in random order in time to the metronome beat. For example $2,5,5,4,1,4,3$, etc. , as if you have a hat in front of you containing the numbers on pieces of paper. You take one of the pieces out and say the number on it aloud, put it back, mix the pieces, then take another number out, say it aloud, and so on."

All subjects were told that $1,000 \mathrm{msec}$ per tap or verbalization was the target performance rate in the secondary tasks, and the subjects were given practice at achieving this while watching the display of rate on the Atari monitor. The screen was then turned away from the subject's view.

\section{Results}

Our approach to the analysis of the results was to compare each dual-task condition with its own control. In all cases, the prediction was that the dual task would impair performance. We also endeavored to identify the probable strategy used by each subject in control and dual conditions and to assess the distribution of strategies over conditions. In addition, evidence relating to possible trading off between primary and secondary tasks was examined.

Response accuracy and strategies. Figure 1 shows the number of correct responses out of 20 for all the control and secondary-task conditions and also indicates the levels of performance expected for the set of syllogisms used on a range of possible strategies (logical, atmosphere, matching, and guessing). The expected performance levels were calculated as follows. According to a logicequivalent strategy, all responses would be correct. For atmosphere and matching, exact predicted responses are made for each problem and yield 12 and 10 correct, respectively, for the 20 problems used in this study. There are 5 alternative responses for each problem (all, some, none, some not, no valid conclusion), and so 4 out of 20 will be correct by pure guessing. The matching-strategy assumption appears to give the best fit to the data in all conditions, including the case of performance with random generation, which is depressed toward, although still above, guessing level. Comparing mean performance under random generation (8.56) with guessing level (4.00) gives a highly significant difference $[t(15)=4.81$, $p<.001$.

Comparing the subjects' control accuracy with their accuracy under secondary-task conditions, no significant effects (one-tail tests) were obtained between tapping $[F(1,15)=0.74$, n.s. $]$ or articulatory suppression $[F(1,15)=0.19$, n.s. $]$ and their control conditions, but there was a significant adverse effect of random generation on accuracy of syllogistic performance $[F(1,15)=$ $3.17, p<.05]$ compared with the relevant control. 


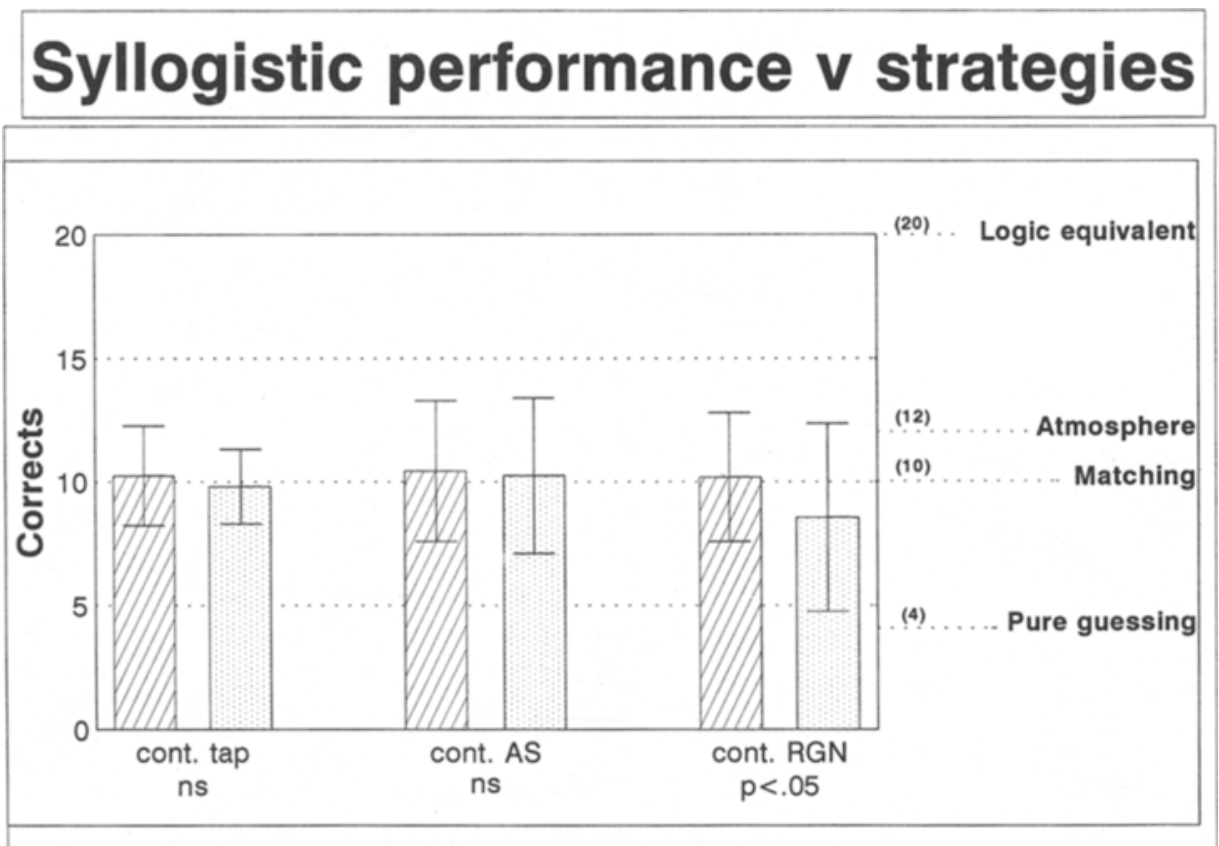

Figure 1. Average syllogistic performance in dual- and control-task conditions (SDs given by bar lines). The expected performance levels for four possible strategies are indicated. cont = control; tap = tapping; $\mathbf{A S}=$ articulatory suppression; $\mathbf{R G N}=$ random generation; $\mathbf{n s}=$ nonsignificant.

A detailed examination of strategies was carried out. Each subject's response to each syllogism in each condition was compared with the responses predicted by the logic, atmosphere, and matching strategies. Thus, for each subject in each condition, the percentage fit of each of the three idealized strategies could be assessed. Some subjects were not fitted well by any of the three idealized strategies and were classed as following a guessing strategy. The criteria used were that at least one of the logic, atmosphere, or matching strategies should fit $55 \%$ or more of the subject's responses; otherwise, the subject was assigned to the guessing category. If the subject was not in the guessing category, then he/she was assigned to the best fitting of the logic, atmosphere, and matching strategies. Ties in goodness of fit were recorded as mixed strategies (e.g., logic/atmosphere).

The resulting distribution of subjects over the strategy categories in the control and dual conditions are shown in Tables 3 and 4 . Overall, $73.7 \%$ of cases were categorized as "pure" examples of a strategy, with the remainder being classed as mixed examples.

The matching strategy was the most common over the control (37.5\% of subjects) and dual (31.9\% of subjects) conditions, whereas guessing increased between control (4.2\% of subjects) and dual (19.2\% of subjects) conditions. The percentage of subjects in the guessing category is particularly marked in the random-generation dual condition $(37.5 \%)$. Chi-square comparisons between the overall frequencies of the strategies in the control conditions and in each dual condition indicated that there was no significant effect of articulatory suppression or of tapping on the distribution of strategies, but there was a marked effect of random generation $\left[\chi^{2}(5)=15.11, p<\right.$ $.01]$. The tendency appears to be for random generation to shift subjects to guessing and away from the relatively more demanding strategies. To check this interpretation, it would be desirable to track individual changes in strategy from control to dual conditions; however, subject numbers were too small in this study to permit the desired tracking.

Latencies. Two latency measures were obtained on each trial: the time to read the premises and formulate a conclusion (premise-processing time) and the time to indicate the chosen conclusion from a menu (conclusionreporting time). The mean premise-processing times per condition are indicated in Figure 2. As with the accuracy measure, only random generation had a significant effect when compared with the corresponding control performance $[F(1,15)=6.64, p<.01]$. The nonsignificant $F$ s for tapping and articulatory suppression were 2.53 and 0.03 , respectively $(d f \mathrm{~s}=1,15)$.

Mean conclusion reporting times per condition are shown in Figure 3. This measure was not significantly affected by any of the secondary tasks. The nonsignificant $F$ s for tapping, articulatory suppression, and random generation were $1.21,0.01$, and 1.02 , respectively $(d f s=$ 1,15 ). The lack of effect for random generation on conclusion-reporting time indicates that the effect of random generation is specific to the premise-processing phase and not simply a general slowing-down effect. 
Table 3

Distribution of Individual Subjects by Type of Task, Condition, and Strategy

\begin{tabular}{|c|c|c|c|c|c|c|c|c|}
\hline \multirow[b]{3}{*}{ Subject } & \multicolumn{2}{|l|}{ Tapping } & \multicolumn{3}{|c|}{ Articulatory Suppression } & \multicolumn{3}{|c|}{ Random Generation } \\
\hline & \multicolumn{2}{|c|}{ Condition } & \multirow[b]{2}{*}{ Subject } & \multicolumn{2}{|c|}{ Condition } & \multirow[b]{2}{*}{ Subject } & \multicolumn{2}{|c|}{ Condition } \\
\hline & Control & Dual & & Control & Dual & & Control & Dual \\
\hline 1 & $\mathrm{M}$ & $M$ & 17 & $\mathrm{~L} / \mathrm{A}$ & $\mathrm{L}$ & 33 & L & $\mathrm{L}$ \\
\hline 2 & $\mathrm{~L}$ & G & 18 & $\mathbf{M}$ & $\bar{M}$ & 34 & $\mathbf{M}$ & $\mathbf{M}$ \\
\hline 3 & $\mathrm{~A}$ & A & 19 & $\mathrm{~L} / \mathrm{A}$ & L & 35 & $\mathbf{M}$ & A \\
\hline 4 & G & $M / A$ & 20 & A & $\mathrm{M} / \mathrm{A}$ & 36 & $\mathrm{~A}$ & A \\
\hline 5 & A & $\mathbf{M}$ & 21 & $\mathbf{M}$ & $\mathbf{M}$ & 37 & G & G \\
\hline 6 & $\mathrm{~L}$ & $\mathbf{L}$ & 22 & $\mathbf{M} / \mathbf{A}$ & $\mathbf{M} / \mathbf{A}$ & 38 & $A$ & $\mathbf{M}$ \\
\hline 7 & $\mathrm{~L}$ & L/A & 23 & $\mathbf{M}$ & $\mathbf{M}$ & 39 & A & A \\
\hline 8 & $\bar{M}$ & $M$ & 24 & $\mathbf{M}$ & $\mathbf{M}$ & 40 & $\mathbf{L}$ & G \\
\hline 9 & A & $\mathrm{M}$ & 25 & $\mathrm{~L} / \mathrm{A}$ & L & 41 & $\mathrm{M} / \mathrm{A}$ & G \\
\hline 10 & A & A & 26 & $\mathbf{M} / \mathbf{A}$ & A & 42 & $\mathrm{M} / \mathrm{A}$ & A \\
\hline 11 & $\mathrm{M} / \mathrm{A}$ & $\mathbf{A}$ & 27 & $\mathbf{M}$ & $\mathbf{M}$ & 43 & $\mathbf{M}$ & G \\
\hline 12 & $\mathrm{M} / \mathrm{A}$ & $\mathbf{G}$ & 28 & $\mathbf{M}$ & $\mathbf{M} / \mathbf{A}$ & 44 & L/A & $\mathbf{G}$ \\
\hline 13. & $\mathbf{M}$ & $\mathbf{M}$ & 29 & $\mathbf{M}$ & $\mathbf{M}$ & 45 & A & A \\
\hline 14 & $\mathbf{M}$ & $\mathrm{M} / \mathrm{A}$ & 30 & $\mathbf{M}$ & G & 46 & $\mathrm{M} / \mathrm{A}$ & $\mathrm{M} / \mathrm{A}$ \\
\hline 15 & $\mathbf{M}$ & $\mathbf{M}$ & 31 & $\mathbf{M} / \mathbf{A}$ & $\mathbf{M} / \mathbf{A}$ & 47 & A & $L / A$ \\
\hline 16 & M & M & 32 & $\mathbf{M}$ & $\mathbf{M}$ & 48 & $\mathbf{M} / \mathbf{A}$ & G \\
\hline
\end{tabular}

Trade-offs. It is always possible that the lack of effect of secondary tasks is due to some trading off such that subjects give low priority to the secondary task in order to maintain performance on the primary task. To check this possibility, we obtained measures of secondary-task performance both as secondary tasks and when performed alone. These comparisons revealed (1) no difference between tapping rates $[F(1,15)=1.12$, n.s. $]$ for single-task tapping ( $M=1.01 \mathrm{sec}$ per tap, $S D=0.013 \mathrm{sec}$ per tap) and dual-task tapping $(M=1.01 \mathrm{sec}$ per tap, $S D=$ $0.048 \mathrm{sec}$ per tap); (2) a small but significant slowing of average articulation rate from $1.03 \mathrm{sec}$ per digit $(S D=$ $0.035 \mathrm{sec}$ per digit) for the single task to $1.09 \mathrm{sec}$ per digit $(S D=0.082$ sec per digit) for the dual task $[F(1,15)=$ $27.92, p<.001$ ]; (3) a significant increase in average redundancy, measured by Evans's (1978) RNG index, of random-generation strings, from $0.51(S D=0.05)$ to $0.57(S D=0.06)$ between single and dual generation $[F(1,15)=11.19, p<.005]$; and (4) a marked and significant slowing of the rate of random generation, from $1.16 \mathrm{sec}$ per digit ( $S D=0.12 \mathrm{sec}$ per digit) to $1.60 \mathrm{sec}$ per digit $(S D=0.043 \mathrm{sec}$ per digit) between single and dual conditions $[F(1,15)=76.11, p<.001]$.

\section{Discussion}

Our interpretation of the above results is as follows. Most of the subjects in all conditions appear to be matching or following the atmosphere strategy most of the time, rather than working through the logic of the syllogistic argument. In the random-generation condition, performance is considerably slowed down and more error prone, indicating that concurrent random generation interferes with matching and atmosphere strategies. However, it is notable that even in this demanding condition, average accuracy of syllogistic performance is comfortably above guessing level.

There was no evidence for involvement of the visuospatial scratch pad, since the concurrent spatial task did not interfere with syllogistic performance (accuracy or latency) and vice versa. This finding goes against some of the models-oriented approaches, which have postulated the use of mental imagery, for example, in the form of

Table 4

Distribution of Subjects by Type of Task, Condition, and Strategy

\begin{tabular}{lllrrrr}
\hline \multicolumn{1}{c}{ Task } & L & L/A & A & A/M & M & G \\
\hline & \multicolumn{2}{c}{ Control Condition } & & & \\
Tapping & 3 & 0 & 4 & 2 & 6 & 1 \\
Articulatory suppression & 0 & 3 & 1 & 3 & 9 & 0 \\
Random generation & 2 & 1 & 5 & 4 & 3 & 1 \\
Total & 5 & 4 & 10 & 9 & 18 & 2 \\
& \multicolumn{2}{c}{ Dual Condition } \\
Tapping & 1 & 1 & & & & \\
Articulatory suppression & 3 & 1 & 1 & 4 & 7 & 2 \\
Random generation & 1 & 1 & 5 & 1 & 2 & 6 \\
Total & 5 & 3 & 9 & 7 & 15 & 9
\end{tabular}

Note $-\mathrm{L}=\operatorname{logic}$ strategy; $\mathrm{A}=$ atmosphere strategy; $\mathrm{M}=$ matching strategy; $\mathrm{G}=$ guessing strategy; $\mathrm{L} / \mathrm{A}$ and $\mathrm{A} / \mathrm{M}=$ mixed strategies. 


\section{Premise processing time}

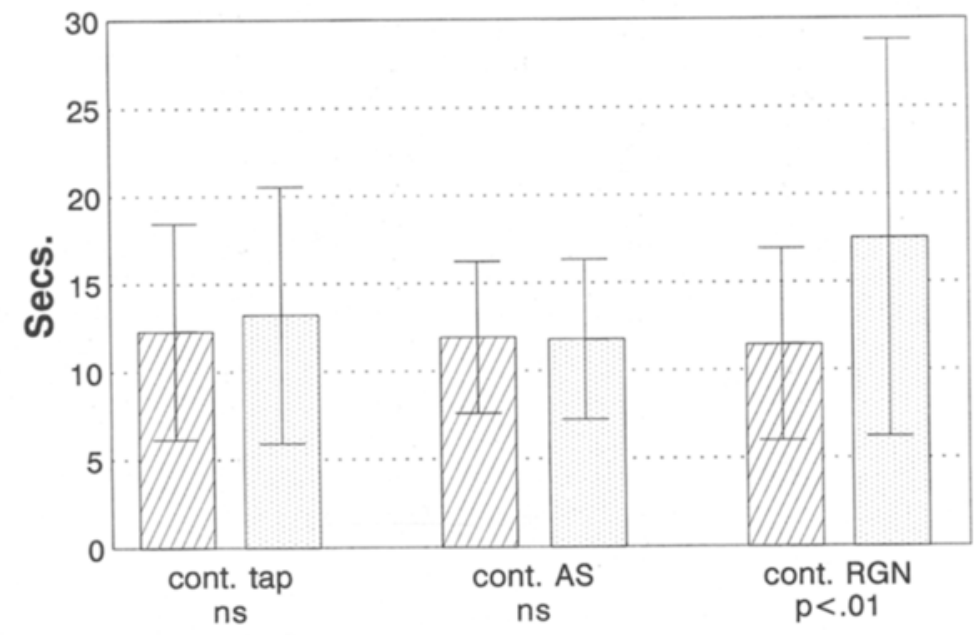

Figure 2. Average premise-processing times in dual- and control-task conditions ( $S D$ s given by bar lines). cont $=$ control; tap $=$ tapping; $\mathbf{A S}=$ articulatory suppression; $\mathbf{R G N}=$ random generation; $\mathrm{ns}=$ nonsignificant.

\section{Conclusion reporting time}

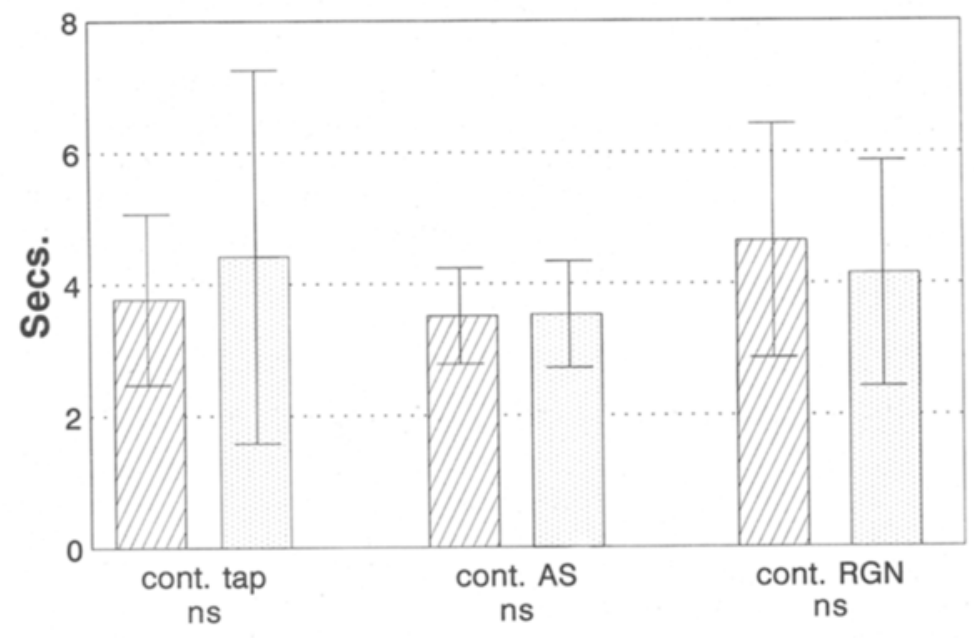

Figure 3. Average conclusion-reporting times in dual- and control-task conditions ( $S D$ s given by bar lines). cont $=$ control; tap = tapping; $\mathbf{A S}=$ articulatory suppression; $\mathbf{R G N}=$ random generation; ns = nonsignificant. 
Euler circles (Erickson, 1974, 1978; Guyote \& Sternberg, 1981). Our subjects appear to have been using, for the most part, fairly superficial "heuristic" strategies, and different results for the involvement of the visuospatial scratch pad may result if subjects are induced to employ strategies requiring deeper processing of the premises.

There was some sign of articulatory-loop involvement in that the syllogism task slightly (but consistently) slowed down concurrent articulation; however, the reverse effect was not demonstrated. This result is consistent with that of Experiment 1, which showed that verbal presentation interfered with syllogistic performance.

A major involvement of the central executive was indicated by the large mutual adverse effects of concurrent random generation and syllogistic-task performance. This is understandable in that all nonguessing strategies, including the modal but relatively undemanding matching strategy, require the processing of different sources of information (the premises must be compared to find the more conservative quantifier), and responses must be generated, selected, and scheduled. The random-generation task was designed to require the processing of different information sources, the generation, selection, and scheduling of responses, which are all seen as the province of the central executive (Baddeley, 1986); hence the observed interference.

\section{GENERAL DISCUSSION}

The overall aim of the present studies was to investigate the role of working memory in syllogistic-reasoning tasks as a special case of problem solving. The results of Experiment 1 indicated that working-memory load was a factor in the processing of sequentially presented premises such as might occur in an oral argument. However, the main effect was on the correct retention of the terms rather than in the integration of the premises, in that the additional errors due to sequential presentation involved redundant "conclusions" involving the middle term (conclusions should always relate subject and predicate terms). Experiment 2 examined the case of visually presented, continuously available premises such as might occur in written arguments. Here, we used dual-task methodology and Baddeley's (1986) tripartite model of working memory. The results indicated no involvement of one "slave", memory system, the visuospatial scratch pad, and a small involvement of the other slave system, the articulatory loop, but a strong involvement of the central executive. These results seem counter to the spirit of modelmanipulating approaches to syllogistic performance in that model manipulation would be expected to load working memory highly, including the slave systems. Indeed, Sternberg (Guyote \& Sternberg, 1981) and Erickson $(1974,1978)$ explicitly propose imagery representations (see also Kirby \& Kosslyn, 1990; Stenning, in press), which should load the visuospatial scratch pad in syllogistic reasoning, but we found no evidence of visuospatialscratch-pad loading in our study. Johnson-Laird (1986) is less specific about the nature of the representation of his mental models, although imagery has been proposed as a possible mode (Kirby \& Kosslyn, 1990). We have discussed the visuospatial scratch pad as a unitary system, but some researchers have argued for a fractionation of the scratch pad into two subsystems, one for spatial and one for visual material (e.g., Farah, Hammond, Levine, \& Calvanio, 1988; Logie, 1989; Reisberg \& Logie, in press). Accepting such a fractionation would leave open the possibility of a strong imagery involvement in syllogistic-task performance, since our loading technique was spatially rather than imagery based. However, given the general level of performance in our study and the analysis of individual strategies, it is plausible to conclude that the subjects were using heuristic strategies (matching or atmosphere; see Table 3), which placed low demands on the "slave" systems but enough of a load on the central executive to be disrupted by random generation.

A general point that emerges from these studies is that it is not experimentally fruitful to ask, "What is the involvement of working memory in syllogistic reasoning?" unless the strategy used in the study can be specified as being a good approximation to" "reasoning." The studies reported here suggest that it might be productive to adopt procedures to induce reasoning-equivalent strategies, for example, sufficient pretraining before the dual-task conditions are applied. Another alternative is to use longer sets of diagnostic problems that would enable subjects to be more reliably categorized into strategy groups. Then, one could examine the involvement of working memory in particular strategies for dealing with syllogistic tasks, where those strategies may or may not be equivalent to correct reasoning.

\section{REFERENCES}

Baddeley, A. (1986). Working memory. Oxford: Oxford University Press.

Baddeley, A. D., Hitch, G. J. (1974). Working memory. In G. Bower (Ed.), Recent advances in learning and motivation (Vol. 8, pp. 47-90). New York: Academic Press.

Baddeley, A. D., Lewis, V. J., \& Vallar, G. (1984). Exploring the articulatory loop. Quarterly Journal of Experimental Psychology, 36, 233-252.

BEGG, I., \& DENNY, J. P. (1969). Empirical reconciliation of atmosphere and conversion interpretations of syllogistic reasoning errors. Journal of Experimental Psychology, 81, 351-354.

Braine, M. D. S. (1978). On the relation between the natural logic of reasoning and standard logic. Psychological Review, 85, 1-21.

Braine, M. D. S., Rumain, B. (1983). Logical reasoning. In J. Flavell \& E. Markman (Eds.), Handbook of child psychology: Vol. 3. Cognitive development (4th ed., pp. 263-340). New York: Wiley.

Dickstein, L. S. (1978). The effect of figure on syllogistic reasoning Memory \& Cognition, 6, 76-83.

ERICKSON, J. R. (1974). A set analysis theory of behavior in a formal syllogistic reasoning task. In R. L. Solso (Ed.), Theories in cognitive psychology: The Loyola Symposium (pp. 305-330). Potomac, MD: Erlbaum.

ERICKson, J. R. (1978). Research on syllogistic reasoning. In R. Revlin \& R. E. Mayer (Eds.), Human reasoning (pp. 39-50). Washington, DC: Winston.

Evans, F. J. (1978). Monitoring attention deployment by random num- 
ber generation: An index to measure subjective randomness. Bulletin of the Psychonomic Society, 12, 35-38

Evans, J. ST. B. T., \& Brooks, P. G. (1981). Competing with reasoning: A test of the working memory hypothesis. Current Psychological Research, 1, 139-147.

Farah, M. J., Hammond, K. M., Levine, D. N., \& Calvanio, R. (1988). Visual and spatial mental imagery: Dissociable systems of representation. Cognitive Psychology, 20, 439-462.

Farmer, E. W., Berman, J. V. F., \& Fletcher, Y. L. (1986). Evidence for a visuo-spatial scratch-pad in working memory. Quarterly Journal of Experimental Psychology, 38A, 675-688.

FisHER, D. L. (1981). A three-factor model of syllogistic reasoning: The study of isolable stages. Memory \& Cognition, 9, 496-514.

Galotti, K. M., Baron, J., \& Sabini, J. P. (1986). Individual differences in syllogistic reasoning: Deduction rules or mental models? Journal of Experimental Psychology: General, 115, 16-25.

GilHooly, K. J. (1988). Thinking: Directed, undirected and creative (2nd ed.). London: Academic Press.

Gilhooly, K. J. (1991). Thinking. In R. Dulbecco (Ed.), Encyclope dia of human biology (pp. 467-472). San Diego: Academic Press.

GuYote, M. J., \& STERNBERG, R. J. (1981). A transitive chain theory of syllogistic reasoning. Cognitive Psychology, 13, 461-525.

Halford, G. S., Bain, J. D., \& Maybery, M. T. (1984). Does a concurrent memory load interfere with reasoning? Current Psychological Research \& Reviews, 3, 14-23.

HrTCH, G. J., \& BADDELEY, A. D. (1976). Verbal reasoning and working memory. Quarterly Journal of Experimental Psychology, 28, 603-621.

Johnson-Laird, P. N. (1983). Mental models. Cambridge: Cambridge University Press.

Johnson-Laird, P. N., \& BARA, B. G. (1984). Syllogistic inference. Cognition, 17, 1-61.

Johnson-Laird, P. N., \& Byrne, R. (1991). Deduction. Hove: Erlbaum.

KIRBY, K. N., \& KossLYN, S. M. (1990). Thinking visually. Mind \& Language, 5, 324-341.

LoGIE, R. H. (1989). Characteristics of visual short-term memory. European Journal of Cognitive Psychology, 1, 275-284

LOGIE, R. H. (1991). Visuo-spatial short term memory: Visual working memory or visual buffer. In C. Cornoldi \& M. McDaniel (Eds.), Imagery and cognition (pp. 77-102). New York: Springer-Verlag.

Logie, R. H., Baddeley, A. D., Mane, A., Donchin, E., \& ShePTAK, R. (1989). Working memory in the acquisition of complex cognitive skills. Acta Psychologica, 71, 53-87.

Logie, R. H., Zucco, G., \& BAdDeley, A. D. (1990). Interference with visual short-term memory. Acta Psychologica, 75, 55-74.

Newell, A., \& Simon, H. A. (1972). Human problem solving. Englewood Cliffs, NJ: Prentice-Hall
Norman, D. A., \& Shallice, T. (1980). Attention to action: Willed and automatic control of behavior (CHIP Report No. 99). San Diego: University of California.

REISBERG, D., \& LoGIE, R. H. (in press). The ins and outs of visual working memory: Overcoming the limits on learning from imagery. In M. Intons-Peterson, B. Roskos-Ewoldsen, \& R. Anderson (Eds.), Imagery, creativity, and discovery: A cognitive approach. Amsterdam: Elsevier.

REVLIS, R. (1975). Two models of syllogistic reasoning. Joumal of Verbal Learning \& Verbal Behavior, 14, 180-195.

Rips, L. J. (1983). Cognitive processes in propositional reasoning. Psychological Review, 90, 38-71.

SAARILUOMA, P. (1991). Visuo-spatial interference and apperception in chess. In R. H. Logie \& M. Denis (Eds.), Mental images in human cognition (pp. 83-94). Amsterdam: North-Holland.

SALWAY, A. F. S. (1991). Random generation in the working memory dual task paradigm. Unpublished doctoral dissertation, University of Aberdeen, Aberdeen, Scotland.

SANFord, A. J. (1985). Cognition and cognitive psychology. London: Weidenfeld \& Nicholson.

SCHNEIDER, W. (1990). MEL user's guide: Computer techniques for real time psychological experimentation. Pittsburgh: Psychology Software Tools.

SELLS, S. B. (1936). The atmosphere effect: An experimental study of reasoning. Archives of Psychology, 200, 1-72.

StenNing, K., \& Oberlander, J. (in press). Spatial inclusion as an analogy for set membership: A case study of analogy at work. In K. Holyoak \& J. Barnden (Eds.), Analogical connections. Hillsdale, NJ: Erlbaum.

Sternberg, R. J., \& Turner, M. E. (1981). Components of syllogistic reasoning. Acta Psychologica, 47, 245-265.

Wason, P. C., \& Johnson-Laird, P. N. (1972). Psychology of reasoning: Structure and content. London: Batsford.

Wetherick, N. E. (1989). Psychology and syllogistic reasoning. Philosophical Psychology, 2, 111-124.

Wetherick, N. E., \& Gilhooly, K. J. (1990). Syllogistic reasoning: Effects of premise order. In K. J. Gilhooly, M. T. G. Keane, R. H. Logie, \& G. Erdos (Eds.), Lines of thinking (Vol. 1, pp. 99-108). Chichester: Wiley.

WILKINS, M. C. (1928). The effect of changed material on the ability to do formal syllogistic reasoning. Archives of Psychology, 16, 83 .

Woodworth, R. J., \& SelLS, S. B. (1935). An atmosphere effect in formal syllogistic reasoning. Joumal of Experimental Psychology, 18, $451-460$.

(Manuscript received September 27, 1990; revision accepted for publication August 7, 1992.) 